\title{
Film as teacher education genre: Developing student agency in the production of \#Taximaths - How children make their world mathematical
}

\begin{abstract}
The article reports on the process of producing a film for students in a university course. The purpose of the production was to make local film material that could assist students in their learning of developmental cognitive psychology theory in general, but specifically also the mathematical cognition of children. Although the students in the production team set out as actors and technical helpers, they gradually appropriated their acting roles and the plot of the story to the extent that they learned the theory that the film was portraying. Not only did they show interest in the psychology texts and the story, but they also developed agency - they became the owners of the film. The argument of this paper is that a multimodal foundation in teacher education can give students multiple semiotic entry points, but also, if given the opportunity to make a dramatic film, they can learn the content of mathematical cognition while learning film production. The article argues that contemporary teacher education programmes are by their very nature briefed to be multimodal, because teachers' work in schools in the $21^{\text {st }}$ century requires more than language text and oral, in-person communication.
\end{abstract}

Keywords: Teacher education, mathematical cognition, instructional documentary, cognitive development, developmental psychology, educational film

Lara Ragpot, University of Johannesburg. Email address: Iragpot@uj.ac.za.

South African Journal of Childhood Education | 2014 4(2): 176-193 | ISSN: 2223-7674 |๔ UJ
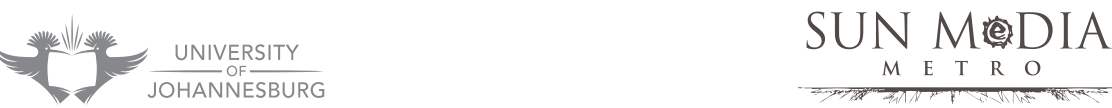


\section{Introduction: The making of an instructional film with teacher education students}

In this article I explore how the making of a film became a vehicle for students to develop their theoretical understanding of mathematical cognition in childhood. Like many other pre-service teacher education students, the ones I teach often struggle to fully comprehend the difficult academic concepts of their course content. Most of the students who study for an education degree at our institution have little exposure to the texts of, for example, cognitive psychology, before they enter university. Moreover, at South African universities in general, students have to engage with academic English, which makes things even harder for those among them who use it is a second language, especially when it comes to academic discourses that often contain incomprehensible, subject-related terms (Seligmann \& Gravett 2010). In the courses on childhood cognitive development, I have found that students struggle to understand and write about the course content and that they mostly recite the content in exams with little evidence of real understanding (Ragpot 2013). Smagorinsky, Cook and Johnson (2003) reported that the students whom they studied seldom grew beyond a preliminary understanding, forming pseudo concepts or complexes (Vygotsky 1978), but not full concepts. Students in the courses that I teach struggle to utilise theoretical terminology to account for their observations of children, even after an entire semester of study. In everyday conversation, however, they do appear to understand children's behaviour very well. I argue that they need to be able to theorise and reflect systematically with knowledge of theory, much as Henning, Petker \& Petersen (in press) have proposed. In order to theorise their experiences of everyday teaching, they need to be able to read dense academic texts, the medium of which is nothing less than daunting. I have always believed that the problem is not a cognitive issue, but a linguistic medium issue. To counter this struggle, I have embarked on an exploration of how to assist students to overcome this difficulty, so that they leave the course with some usable knowledge for the classroom. I experimented with various different tools and modalities over the years.

In the quest to make course content more accessible for students, specifically in the subject area of childhood cognitive development, I have, with reasonable success, incorporated multimodal learning and assessment activities into the curriculum. These activities require students to engage with subject content in varied ways, utilising multiple modes of engagement, such as visual art, drama and music. I have found that even though students struggle with language use, they are not only creative, but also get to understand themes of study more clearly if the mode of engagement varies. These different modalities somehow open up avenues of cognitive integration, leading to different access routes of conceptualisation (Ragpot 2013) beyond the written word. Researchers in the cognitive and neurosciences, such as Winner and Hetland (2007), are of the view that the arts support learning across multiple domains of representation. Cross, Hamilton and Grafton (2006), have demonstrated how music and dance assist memory processes through the mediation of mirror neurons. Stevenson and Deasy (2005) identified learning capacities that are fostered by the 
arts, such as persistence in sustaining concentrated attention on a task and symbolic understanding, through using multiple modes to communicate ideas.

Many educators make use of film as a genre of teaching and I have often used this genre, more specifically, excerpts from documentaries. Although these extracts are informative, such as a short documentary on brain plasticity, ${ }^{1}$ they don't always address a topic in a way that is functional for teacher education purposes. For example, if I wish to discuss brain plasticity in terms of a child's functioning in a Grade 1 classroom, the film itself has limited use as a tool unless the film maker had a similar teaching objective in mind. Also, more often than not, these short documentaries present a specific Westernised view, exemplified in the cases they include. The context and the type of English used are strange to most of the students who study at our institution; for instance, the students might not know how to position the image of an American kindergartener in a MIT child cognition lab² in terms of the children they observe in the South African education system. So although students respond well to film as a teaching genre, I often have to spend much time during the showing of film excerpts to explain vocabulary, concepts and context.

These observations led me, along with my then doctoral supervisor, to ask the question: what if film could be incorporated into the coursework by not only utilising an existing film, but by actually making the film? In this type of endeavour, the different aspects of the film, such as script, mise en scène, acting and direction could be tailormade to suit both the themes of the course as well as the students taking the course, and, above all, it use local English, interspersed with the discourse of the texts they studied. The idea was that the final product, with a combined emphasis on teacher education and cognitive psychology, could then be used as a teaching tool in lectures. Students could have multiple entries into the learning content by making use of multiple modes of engagement in, with, and through the film. For this tool to work, it would have to be creative, original, appeal to student's interests, and 'cross-articulate' course content with the world with which they are familiar. The genesis of the project to create a film for teacher education unfolded in line with these ideas, and so \#Taximaths: how children make their worlds mathematical was conceived and produced.

\section{A film about mathematical cognition in childhood}

The film has a central focus: difficult concepts about cognitive development in mathematics, specifically number concept development and calculation, are scripted into everyday scenes in a South African urban ‘township' setting, with identifiable characters and scenes. It was produced with funding secured from the European Union in a South African Department of Higher Education and Training (DHET) project on foundation phase (elementary) teacher education development, and the content was planned to coincide with the DHET-EU funded project at the Centre for Education Practice Research at the University of Johannesburg (CEPR), under directorship of Prof Elizabeth Henning. The film, as a medium, was created to ultimately assist pre-service teachers to move from one way of understanding child mathematical cognition (tacit understanding) to another: a theoretical model of mathematical cognition (Fritz, Ehlert \& Balzer 2013a). 
The conceptual model of mathematical concept development on which the film is based forms part of the curriculum in a second year child development course. It is a hierarchical model of young children's mathematical concept development. The model (Fritz et al 2013a) was designed after extensive empirical research and study of the literature in the fields of developmental psychology, cognitive psychology, mathematical didactics, and the neuropsychology of early childhood conceptual development of numeracy (see also Fritz, Balzer, Ehlert, Herholdt, Ragpot \& Henning [in this issue]).

According to the model, some numerical concepts are already present pre-linguistically (Ansari \& Karmiloff-Smith 2002; Butterworth 1999, 2012; Carey 2004; Dehaene 2011; Fuson 1988; Geary 1993; Kaufmann \& Nuerk 2005; Piaget 1965; Spelke 2000; Steffe, Cobb \& Von Glasersfeld 1988) and develop incrementally when children use language symbols (Henning \& Ragpot, in press). The fundamental assumption on which the model is based is that children's "key numerical concepts develop step by step [... and] are based on one another [...] slowly becoming more elaborate and abstract as the child develops" (Fritz et al 2013a:40). Each step is marked by a specific concept that requires certain cognitive processes and the existence of a concept, which is externalised in the child's use of language and manipulatives to show understanding. However, two forms of mathematical concepts, such as the approximate number system (ANS) and exact number knowledge of up to three objects (known as the object tracking system, or the OTS), are already present in pre-linguistic children (Henning \& Ragpot, in press). The Fritz et al model (2013a) further holds that children not only recognise quantities and learn to calculate small numbers incrementally, but that number symbols (both Arabic and verbal) become known as tools or representation. The hierarchical competence model permits "a description of the performance of a child according to a specific level in the model" (Fritz, Ricken, Balzer, Willmes \& Leutner 2013b).

To capture these abstract concepts in film modality was a challenging task. In the rest of this article I will discuss the making of the film and how it could convert expository text into dramatic film material that may serve as an instructional tool for pre-service education students. The discussion begins with some thoughts on the use of multimodal activities for teaching in higher education. Thereafter, I will look analytically at film as a pedagogical tool in general, and then more specifically the making of documentaries. An outline of the film plot and episodes (chapters) follows, along with 1) the argument for a specific type of script, which stays close to the everyday experiences of students in Soweto; 2 ) the narrative script, with its central storyline of anxiety about the students' forthcoming exam; 3) the characters that were created to allow not only for conflict and drama, but also invited humour into the action; and 5) the locations of various scenes. The experiences of the production team are discussed towards the end of the article. I argue that their contribution to the learning experience of not only film-making, but also learning about the developing mind of the mathematical child, was surprisingly powerful. Before that, however, expanding on the introduction to the article, I put forward the argument 
that $21^{\text {st }}$ century higher education is by definition multimodal and interactive, and that students who struggle with new discourses can benefit from different modes of representation. The semiotic mediation of which Vygotsky $(1978 ; 1986)$ speaks is meant to include all forms of semiotic, as suited to the object of study.

\section{Multimodal mediation in higher education}

Firstly I would like to clarify the use of the term 'multimodal' in the context of this article. In the domain of semiotics, a 'modality' denotes a particular way in which information is encoded for presentation and communication (Danesi 2007). Meaning is conceived/ constructed as the effect of a set of signs (in lexical or any other form) when a reference is made to an object and the sign (or 'representamen') is interpreted recursively by another sign, which becomes its 'interpretant' (Deely 2005). Thus signs meet up in the process of meaning-making and the semantics are conjointly arrived at. Combinations of types of signs can thus be multimodal, in other words, there can be different types of signs grouped together for 'cognitive effect' in different modalities. In terms of this article, 'multimodality' refers to the different signs that were used in creating learning opportunities. Language, though primary, was not the only recourse for expressing understanding of concepts. The props, scenes, clothes and costumes, dramatic tension, characterisation, conflict and eventual denouement were all 'signatories' to the eventual semiotic.

In my doctoral study on this type of representation of students' understanding (Ragpot 2013), the findings confirmed, among other things, that a multimodal approach to curriculum design and assessment was conducive to student learning. The results showed that students could be supported in their learning to a surprising extent by way of multiple representation modes. Another noteworthy finding was that, in the end, the students did use the new discourse in their writing in a way that showed their understanding of it - unlike what I had seen in previous courses, where they had simply reproduced sections of texts which had been learned by rote. They were also able to relate theories in an analytical way and to see their personal encounters with empirical reality through a newly acquired theoretical lens which they had developed though drama, play, singing, dance and art. They were assessed in other modalities beyond just the written word and expressed themselves reasonably clearly in dramatic play productions and artistic portrayals of learning content, such as collages, drawings and even stage props. The study highlighted the fact that the students' learning was not characterised by a rehash of ideas from the literature, but by true engagement with the theory via mixed modes of interaction, such as class discussions, the production of collages and videos, photography, and the extensive use of metaphors. It became clear that what had started out of concern for the students' understanding of difficult English texts culminated in what seems to be a powerful pedagogic tool for teacher education.

\section{Film as pedagogical tool and bridge to student agency}

Although the \#Taximaths film was made with the help of a production company and a professional director, amateurs were responsible for other components, such as the 
scriptwriting, casting and design of the scenes. The subject content was purposefully chosen, but the making of the film was more organic and ideas developed as the film progressed. The film thus contains elements of professional film-making, but also incorporates academic and amateur elements. The scriptwriters were not experts on the technical aspects of film production or certain stylistic elements of film as genre (specifically documentaries), but learned as the production progressed.

Although the film does not really fit any conventional subtype of the film genre, it may be regarded as part documentary and part dramatic fiction. It is a documentary, as it has a subject (mathematical cognition), but it is also fiction, as it has a story with a set of characters who "move through a series of events in a forward direction compelled by a series of actions and reactions" (Anderson 2014:5). As a documentary, the film does not really fit into any style of this type of film genre. On the one hand, it was made in the interactive/reflexive style or 'mode' (Nichols 2001) of documentary; on the other, there are some elements of the 'performative' documentary style (Anderson 2014). Annemarie Fritz and co-authors, as the developers of the conceptual model, are introduced to the audience and Fritz is interviewed on camera in a direct address to the audience. In true 'performative' documentary style (Nichols 2001), the film-maker, who is the subject of the film, undergoes a visceral change in the course of the film (Anderson 2014); in \#Taximaths, the fictional characters undergo a change in their understanding of children's mathematical cognition, hence it fits loosely into the performative mould. But the film leans more towards the interactive documentary style: as film-makers we did not try to conceal that we were making a film that was specifically intended to serve as pedagogical tool. An example of this is the prologue, where the audience is addressed directly by one of the main characters, Claire, who introduces the model of mathematical concept development - the main subject matter of the film. The character also briefly outlines the development of the film over five episodes (or 'chapters', as they are referred to in the series) and explicitly communicates the intended use of the film as a pedagogical tool for teacher education. If need be, \#Taximaths could be described as a 'performative instructional documentary', but I agree with Anderson that it is not the style of a specific genre of film that is important, but rather what the audience expects from the film and the intention with which it is made (ibid).

\#Taximaths had a threefold intention, specifically focusing on audience, content and purpose. The film was made with a specific audience in mind (pre-service education students, teachers of young children, and educational psychologists); focuses on a specific subject matter as content (young children's mathematical cognition); and was made with the intent of creating a teacher education resource that could be shared with other universities in South Africa (Parker 2010). Apart from intention, other important elements of film-making, such as soundtrack, inter-titles, camera angles and context (Anderson 2014), were also kept in mind. Added to these, general issues of importance to film-making, such as script, plot and characterisation (Bernard 2014) had to be carefully considered. 
Documentaries have mainly been used in sociology classes in higher education (Daniels 2014). Tessa Miller, who was involved in the making of a documentary about Attica prison in the United States which she uses as a teaching tool in her law courses, asserts that "the way in which the documentary process is undertaken is vital to its value as a teaching tool" (Miller 2012:232). Miller notes that though the use of film as a teaching tool has gained momentum, the actual making of films, such as documentaries, has not (ibid). She goes on to say that students have a different experience when they see the theoretical content discussed in academic classes represented in real-life situations outside the classroom, and that the process becomes exponentially more powerful when they are involved in the actual film-making. I agree with Miller that involving students in the actual process of film-making outside the classroom brings them into first-hand contact with the practical application of the course content. They experience how each line of dialogue, each prop and each intonation suggested by the director helps them to understand the discourse and the previously 'strange' terminology. Added to that, I believe that this experience does not only affect the students who are involved in the actual film-making process, but also the students to whom the film is shown, as they witness how the making of the film empowers their classmates and how they become agents of their own learning. This was clear throughout the production process: what was previously strange discourse in the context of an academic English milieu in the developed world became local, South African - became their cultural capital. They started to own the theories of Susan Carey, Alison Gopnik, Elizabeth Spelke and Stanislas Dehaene. They made it their own because they were producing the film in their own context, with their own lives as the stage. They were no longer standing in the wings of academia.

This is the central argument of the article: I assert that if students are able to strongly/easily identify with characters (their friends and people they can relate to) on screen while these characters go through various experiences - such as struggling with the abstract theoretical content of course work in real-world situations - it may capture their interest and possibly raise their understanding of the content to another level. More than anything though, it removes the power of the powerful discourse and the students can make it visibly, tangibly, their own by means through dialogue, action and dramatic plot. They become powerful agents, not only in their own conceptual development, but also in the development of learning content. Some of these issues will be explained in the next section.

\section{\#Taximaths: From conceptualisation to completed artefact}

In 2011 the DHET invited all South African teacher education institutions to produce teacher education tools that could be shared among the different universities in their foundation phase education programmes (RSA DHET 2010). At the University of Johannesburg (UJ), this work was situated within the Centre for Education Practice Research (CEPR). The decision was taken to make a film as an alternative teacher education tool to workbooks or text-based material (although the \#Taximaths film series also has an e-book which accompanies it). Some other universities also opted 
for the film medium, but in the mode of filming a particular lecture or school classroom lesson. As a creative team at UJ, we opted for a scripted and focused approach in our film, utilising content that was not primarily pedagogical, but rather about developmental psychology. Much emphasis is placed on the needs of children in the UJ programmes for primary school education. In mathematics learning, we argued, future teachers need to know about the typical ways in which children learn maths concepts. We had a conceptual model that had been tried and tested in Germany and in South African research (Fritz et al in this volume) at our disposal, and so we opted to take this model as the theme of the film.

There is also a reason why we used the focus point of a taxi. The idea for the taxi came from a play which the students had developed and performed in 2011 for an assignment in a course on cognitive development. They made the point that there is much maths talk in taxis. In the play, there was scene where a school pupil got onto the taxi and had trouble counting her money; different passengers in the taxi gave their views on the reason for her inability to get to the correct answer, each based on a specific theoretical point of view on childhood mathematical conceptual development. The taxi thus became the vehicle, literally and figuratively, for exploring the mathematical conceptual development of the child.

As developers of the film, we used the hash symbol (\#), in the convention of Twitter hashtags, to differentiate the name \#Taximaths. Hashtags were originally created on Twitter "as a way to help organise and find tweets on specific topics, much like how file folders and sticky notes in book pages work". ${ }^{3}$ In \#Taximaths, we subscribed to the meaning of the hashtag as a form of adding metadata to tweets or in this case, adding metadata to our film. The Twitter-type language was also used as a means to reach the intended audience of the film, namely young, pre-service education students.

The script was developed in a rather ad hoc style, with each episode loosely centred on a level of the Fritz et al model (see Fritz et al 2013a,b; and in this volume). Other concepts of mathematical development and conceptual change in childhood, as well as neurological views of learning by neuroscientists such as Dehaene (2011), were also incorporated into the script content. The script also grew and developed during the filming process as the students added their own ideas. Thus the original script only served as an outline and guideline to establish the scenario and spontaneous additions abounded, demonstrating that the students were indeed becoming active agents in the learning experience.

The film begins with a general prologue, followed by five chapters that focus on the five levels of the Fritz et al model (Fritz et al 2013a,b; and in this volume). The prologue introduces the viewer to a schoolteacher (acted by a fourth-year student) who briefly outlines the main names and ideas of the model. Prof Annemarie Fritz, one of the minds behind the conceptualisation of the model, is then interviewed by one of the main characters in the film. After that, another main character gives the viewer an overview and explains the purpose of each of the five chapters or episodes. 
Chapter 1 focuses on level one of the model, which we named 'Counting and knowing' in the film. Chapter 2 and 3 explore 'Numbers in order'. Chapter 4, 'How many in a group?', looks at cardinality of number and Chapter 5 includes the concept of part-part-whole ('Numbers within numbers') and the relationships of numbers with other numbers ('Number Patterns'). The titles of the chapters in the film are intentionally less abstract than the academic versions in the conceptual model. In a deliberate effort to highlight the fluidity and organic nature of children's mathematical concept development, the chapters also do not follow the exact hierarchy of the model (as the Claire character explains in the prologue), because although childhood mathematical conceptual development is theoretically hierarchic and empirically proven to follow this order, the students insisted that one can never predict precisely how young children may progress and how dynamically the process may unfold. The project leaders deferred to the students' strong stance on this, thus giving them further agency in their development of the concepts and the film as pedagogical tool.

\title{
Dramatic elements: plot, characterisation and mise en scène
}

The design elements of the film were planned beforehand, but many elements were incorporated as the filming progressed, with students providing consistent input. It was evident during the filming that, as they gained self-confidence in the production side of the filming, they also gained knowledge of the topic.

The series captures moments in a group of university students' journey towards understanding the course content of mathematical cognition in children. The DVD cover booklet captures the essence of this experience:

\begin{abstract}
We see a small learning community develop in a course over one semester and with it, the viewer gets a glimpse of how students engage with new theoretical ideas and how they try to mould them into practice for the classroom. We share their learning of a new discourse of cognitive developmental psychology, including some neuroscience, and see, also, their talent in learning multimodally. With Zuki and her classmates, the story unfolds of how they struggle to understand the development of the young mathematical mind of the foundation phase (elementary school) child. With some playful banter and lots of instruction from the two 'tutors' Jerry and Claire, the students come to grips with the mysteries of innate knowledge and of symbolic learning. We see them engage with notions such as core knowledge and approximate number system. We share their discovery of knowledge about the human brain and the neurological connections in learning about analogue magnitude of number, space and time. The group of students visit a school and observe children's learning of mathematical concepts in an actual classroom.
\end{abstract}

(CEPR 2013)

Inserts are used as students convey their real-life experiences of concepts under discussion in tutorials; for example, scenes of characters interacting with children and mothers in a minibus taxi or with children at an athletics meeting, and a mother baking with her children. The student audience can identify with the real-life incidents, situations and environments experienced by the on-screen students, so that the learning experience remains authentic as the plot unfolds and the tension increases towards the end of the term. Dialogue, actions, animations and characterisation all 
contribute to the build-up towards the climax, capturing the attention of the intended audience while still articulating the theory - superficially and playfully at first, but gradually more in depth and seriously.

Like the intended audience of the film, the on-screen characters are aspiring teachers - the idea being that they should represent the students in the audience. Like the characters they portray, the student actors want to learn about the developing mind of the child and want to eventually teach with this knowledge in mind; hence they play their roles convincingly. What characters and audience have in common is that they want to be good teachers. There is thus an awareness of the value of education in the film: the students want to be a new generation of South African primary school teachers who base their practice on a deep understanding of how children develop concepts and how language features in this process. The audience can identify with the on-screen students' suggestions of how to teach and how they find friendship and joy in their common quest to understand young children's minds. Although some of the characters are competitive, they mostly poke fun at each other and have fun together as they share their emergent understanding - errors and all. Essentially, when one watches the film, one becomes aware of how they are building a little community of practice in their tutorial group. ${ }^{4}$

\section{The narrative: Getting to know the conceptual model and the discourse of mathematical cognition in childhood}

The narrative unfolds with the students' tutor, Jerry, and his educational alliance partner, Claire, assisting the group with gentle but firm tutoring. The viewer gets to know the characters at an urban university. Their panic about a term test is infectious; their joy and creativity, too. Their stumbling journey of theorising the conceptual development of maths is a vividly and somewhat uniquely South African experience, with each chapter or episode ending in a rap song (or 'rap') delivered by one of the characters, Chi, in which he beats out his own summarised understanding of the hard theory the group must to get to know. However, the rap does more than just summarise the content, it also utilises the unique talent of the student portraying Chi to create a contemporary, poetic comment on the content of the film. It is not only written by the character Chi in the film, but was scripted in real life by the student who plays the character. Although the original scriptwriters scanned the content of the rap for accuracy, they made as little change as possible to this artistic contribution. In the following excerpt from the rap at the end of Chapter 3, which focuses on the content of Chapter 2 and 3 ('Numbers in order' and 'How many in a group?'), Chi cleverly summarises and also critiques the idea that children should know more than just a horizontal number line:

Like climbing a ladder counting the rungs progressive numbers grow, as preceding digits don't creating mental visions Don't teach them number lines, teach them number games instead, so that they can navigate through all the ideas in their heads 
The idea to use rap in the film came about when the student who play Chi performed a rap he had written during a lecture session instead of handing in a written summary of a specific theory. I recognised his talent and the opportunity it would give him to contribute to the film, and also saw how it could serve to place a strong (and novel) emphasis on the content of each episode. The character thus became the critical voice of each chapter and the student playing him a powerful agent in the creation of each unique comment.

The film also made use of other artistic forms of expression, such as dance. Because dance is such an integral part of South African culture and plays a major role in traditional storytelling and ceremonial practices (Erasmus 2008), it was decided that a dance sequence should feature somewhere in the film. Since we wanted the dance sequence to be accessible to the students, we opted for a modern dance genre of instead of a traditional one. Here again, the students made their voices heard with regard to the specific form of dance we should include in order for it to 'speak to' the modern South African student. Thus we were introduced to 'stepping', which is featured in the first episode of the film. Stepping originally developed in the United States, but South Africa has developed its own unique version of the genre, as evidenced by many video clips on YouTube. The first professionally recorded and edited truly South African stepping video was produced by Gavin Langley (BASEMENT JAM: Slimz" and posted on YouTube in May 2011.5 The dance sequence used in the film is another video produced by Langley, BASEMENT JAMS: Elias and Hops. ${ }^{6}$ One of the dancers in the clip is a personal friend of one of the students, so we duly contacted the producer, who gave us permission to include part of the sequence in \#Taximaths. The stepping clip is used to illustrate a scene in Chapter 1 where the patterns in maths are related to the patterns and sequence in dance. Once again, the students became so actively involved in generating the film content that they suggested incorporating their everyday activities (watching stepping clips on YouTube and doing the moves themselves) into the script.

Characterisation in the film was very deliberate and carefully planned to fulfil specific roles. The on-screen students needed to be optimally representative of the typical mix of students one would find in a third-year pre-service teacher education group. Names, character traits and levels of understanding were all chosen to be representative of South African students. The various characters are introduced in Table 1 in terms of their characterisation and the intention behind each. 
Table 1: \#Taximaths characters

\begin{tabular}{|c|c|c|}
\hline $\begin{array}{l}\text { Character } \\
\text { name }\end{array}$ & Brief character description & Function of character \\
\hline Lesedi & $\begin{array}{l}\text { A newly qualified foundation phase } \\
\text { teacher who is able to give examples } \\
\text { from her teaching where theory comes } \\
\text { alive in the day-to-day teaching in } \\
\text { the classroom. It is her class that the } \\
\text { students visit in Chapter } 4 \text {. She is also } \\
\text { one of the characters who have passed } \\
\text { the course and therefore 'knows' the } \\
\text { course content well. }\end{array}$ & $\begin{array}{l}\text { Lesedi represents who the students } \\
\text { want to be in future: a qualified } \\
\text { teacher with her own classroom } \\
\text { and learners. The purpose of the } \\
\text { character is to establish an explicit } \\
\text { link between the course content and } \\
\text { classroom application. }\end{array}$ \\
\hline Jerry & $\begin{array}{l}\text { Tutor for the third-year course in } \\
\text { Childhood Cognitive Development - } \\
\text { Mathematical Cognition. }\end{array}$ & $\begin{array}{l}\text { Jerry represents the more } \\
\text { knowledgeable voice. He provides } \\
\text { facts from theory and explains difficult } \\
\text { concepts to the students. }\end{array}$ \\
\hline Claire & $\begin{array}{l}\text { Tutor for the fourth-year course in } \\
\text { Childhood Development. }\end{array}$ & $\begin{array}{l}\text { Claire supports Jerry in that the } \\
\text { theory is broken down into more } \\
\text { accessible chunks of information. She } \\
\text { will often add to what Jerry had said } \\
\text { and use different examples to further } \\
\text { explain concepts. }\end{array}$ \\
\hline Zukie & $\begin{array}{l}\text { The 'star' student of the third-year } \\
\text { group - she always does extra reading! }\end{array}$ & $\begin{array}{l}\text { Zukie's character provides extra } \\
\text { information for students who want } \\
\text { to know more and have an extended } \\
\text { view of the topic. }\end{array}$ \\
\hline Ntsiki & $\begin{array}{l}\text { A fourth-year student who creates a bit } \\
\text { of tension, as she is prone to stealing } \\
\text { Zukie's limelight. }\end{array}$ & $\begin{array}{l}\text { Ntsiki often explains Zukie's examples } \\
\text { in more accessible language. }\end{array}$ \\
\hline Kagee & $\begin{array}{l}\text { Supposedly the struggling student } \\
\text { in the class, but he is not scared to } \\
\text { say that he does not understand and } \\
\text { that he needs help and clarification. } \\
\text { Unintentionally, Kagee is a constant } \\
\text { source of mirth for the rest of the } \\
\text { group and seems to enjoy this. }\end{array}$ & $\begin{array}{l}\text { Kagee's character was created to } \\
\text { provide a platform for the reiteration } \\
\text { of ideas mentioned by other } \\
\text { characters, but on a very basic level. } \\
\text { As he often asks for clarification, he } \\
\text { creates the opportunity for these ideas } \\
\text { and concepts to be put into simplified } \\
\text { language and to be translated into } \\
\text { isiZulu or Sesotho. The device was } \\
\text { intended to assist those students in } \\
\text { the audience who struggle with the } \\
\text { English language or perhaps need to } \\
\text { hear concepts explained repeatedly } \\
\text { and in different ways in order to } \\
\text { understand them. }\end{array}$ \\
\hline
\end{tabular}




\begin{tabular}{|c|c|c|}
\hline $\begin{array}{l}\text { Character } \\
\text { name }\end{array}$ & Brief character description & Function of character \\
\hline Noma & $\begin{array}{l}\text { An average student who tries her best } \\
\text { to understand the content and who } \\
\text { summarises the tutorial discussions. } \\
\text { She is often the one who clarifies } \\
\text { concepts for Kagee. }\end{array}$ & $\begin{array}{l}\text { Norma's character answers Kagee's } \\
\text { questions in very concrete terms. } \\
\text { She often gives the most practical } \\
\text { examples and uses physical aids like } \\
\text { pens and money to explain concepts }\end{array}$ \\
\hline Tsepo & $\begin{array}{l}\text { A third-year BEd Foundation Phase } \\
\text { student who is struggling to make the } \\
\text { connection between the theory about } \\
\text { children's mathematical cognition he } \\
\text { learns in his course work at university } \\
\text { and examples in real life. }\end{array}$ & $\begin{array}{l}\text { Tsepo serves as counterpoint to the } \\
\text { Lesedi character, asking theoretical } \\
\text { questions that provide a springboard } \\
\text { for her practical explanations. }\end{array}$ \\
\hline Memani & $\begin{array}{l}\text { A withdrawn student who works } \\
\text { hard and often does extra reading, } \\
\text { but struggles to integrate what he } \\
\text { has read with the examples given in } \\
\text { the tutorial. }\end{array}$ & \multirow{2}{*}{$\begin{array}{l}\text { Sibu and Memani's characters were } \\
\text { included in the storyline to provide } \\
\text { comic relief and ask questions that } \\
\text { allow the tutors to further elaborate } \\
\text { on certain concepts. }\end{array}$} \\
\hline Sibu & $\begin{array}{l}\text { Memani's friend and an intelligent } \\
\text { student who often asks very insightful } \\
\text { questions. Sibu has a humorous } \\
\text { disposition and frequently makes the } \\
\text { group laugh. }\end{array}$ & \\
\hline Chi & $\begin{array}{l}\text { He never comments during the tutorial } \\
\text { discussion, but summarises and ties } \\
\text { all the ideas expressed during the } \\
\text { session together in a rap at the end of } \\
\text { each chapter. The kids at the school } \\
\text { love him. }\end{array}$ & $\begin{array}{l}\text { He is the silent observer and 'critical } \\
\text { voice' of the group. }\end{array}$ \\
\hline
\end{tabular}

\section{Discussion: Bridging the divide between high theory and student learning and enactment}

In the introduction to this article I mentioned that one of the surprising elements of this endeavour was the way in which the students embraced both their roles in the film and their roles in real-life as students who study challenging theoretical topics. As much as drama theory has been cited as educational tool for learning in primary school, the multimodality avenue that the making of this film offered students came as a surprise to us. My doctoral studies had already shown me the value of multiple forms of expression and representation, but I did not foresee the extent to which the eleven students who participated in the making of this film would appropriate not only the medium, but also the message. The film-making itself became a powerful learning tool for them. The comments by some of the students (Table 2) attest to the benefits of this experience. 
Table 2: Comments from actors showing how they benefitted from their participation in the film

\begin{tabular}{|c|c|c|}
\hline $\begin{array}{l}\text { Character } \\
\text { in film }\end{array}$ & Student in real life & Comment \\
\hline Noma & $\begin{array}{l}\text { Fourth-year pre-graduate BEd teacher } \\
\text { education student and tutor for the } \\
\text { second-year course on Cognitive } \\
\text { Development }\end{array}$ & $\begin{array}{l}\text { "The film helped me to make more } \\
\text { sense of the concepts and I could } \\
\text { teach it to the students in tutorials } \\
\text { with real-life examples as we used in } \\
\text { the film." }\end{array}$ \\
\hline Claire & $\begin{array}{l}\text { Third-year pre-graduate BEd teacher } \\
\text { education student }\end{array}$ & $\begin{array}{l}\text { "This year I am the tutor for the } \\
\text { students' practical at the Funda } \\
\text { UJabule teaching school on campus. } \\
\text { The practical examples in the film } \\
\text { and the way in which my character, } \\
\text { Claire, in the film outlined concepts } \\
\text { in a step-by-step logical order, helped } \\
\text { me to do the same in my tutor duties } \\
\text { when the students are preparing } \\
\text { lessons on maths." }\end{array}$ \\
\hline Kagee & $\begin{array}{l}\text { Third-year pre-graduate BEd teacher } \\
\text { education student }\end{array}$ & $\begin{array}{l}\text { "Because my character always asked } \\
\text { these questions which everyone } \\
\text { else understood, it made me feel } \\
\text { that I was there for that student } \\
\text { who would really not make sense } \\
\text { of all this difficult work, and when I } \\
\text { asked the question, I asked it for all } \\
\text { struggling students." }\end{array}$ \\
\hline Zukie & $\begin{array}{l}\text { Third-year pre-graduate BEd teacher } \\
\text { education student }\end{array}$ & $\begin{array}{l}\text { "The film inspired me to go beyond } \\
\text { the minimum requirement in my } \\
\text { studies. As Zukie's character was } \\
\text { always doing extra reading, it inspired } \\
\text { me to also do this. I have also met } \\
\text { students on campus who have been } \\
\text { watching the film in the second-year } \\
\text { course, and they said that they did } \\
\text { some of the reading that I suggest in } \\
\text { the film. This made me proud." }\end{array}$ \\
\hline Lesedi & First-year Grade 1 teacher & $\begin{array}{l}\text { "As I am now really a teacher this } \\
\text { year, I often use examples from the } \\
\text { film (such as the counting sequence in } \\
\text { the taxi, where the little girl counted } \\
\text { the row of sweets from the beginning } \\
\text { each time) in my class to see where my } \\
\text { Grade } 1 \text { children are in terms of their } \\
\text { level of understanding in maths." }\end{array}$ \\
\hline
\end{tabular}




\begin{tabular}{|l|l|l|}
\hline $\begin{array}{c}\text { Character } \\
\text { in film }\end{array}$ & \multicolumn{1}{|c|}{ Student in real life } & \multicolumn{1}{c|}{ Comment } \\
\hline Chi & $\begin{array}{l}\text { Fourth-year pre-graduate BEd teacher } \\
\text { education student }\end{array}$ & $\begin{array}{l}\text { "The long hours of sitting through the } \\
\text { scenes were often frustrating for me } \\
\text { as my character never said a word in } \\
\text { the scenes, but just in the raps. In the } \\
\text { end when I had to write exam in real } \\
\text { life on the course content, I realized } \\
\text { how much I had learned during } \\
\text { filming, just because things were made } \\
\text { so practical." }\end{array}$ \\
\hline
\end{tabular}

Apart from the observed benefit for the participants, other students also benefitted. UJ students now use the film as an object of study in their study groups. As important, though, has been the use of the film in teacher development. Henning (2013) argues that teachers who study not only pedagogy, but also the psychology of child development in mathematics, change their discourse and gradually also their practice. With this in mind, funding has already been procured for the next in the film series of the UJ Department of Childhood Education and the CEPR. As with \#Taximaths, this series will also integrate research on child cognition. In the case of the new film, entitled \#Spazascience: how children learn to see their world scientifically, the film work will be preceded by research on children's ideas of the natural world that is currently being conducted by the Henning working group with funding by the National Research Foundation. In the longer term, there will also be films about learning to be literate in the English of primary school mathematics and science.

The production model of working with a professional production company and artistic director, but using student actors, is unlikely to change. In fact, having the students actively participate in the process of making the \#Taximaths film and seeing how they appropriated it as a medium and tool for learning is likely to be the most lasting educational value of this venture.

\section{Acknowledgement}

The production of the \#Taximaths film was made possible by DHET/EU funding for the UJ project in the Strengthening Foundation Phase Teacher Education (2011-2013) programme.

I wish to thank the project leader, Prof Elizabeth Henning, for her guiding role in the making of the film and the writing of this article.

Thank you also to Jessica Denyschen and her production team, and educational film director Megan Godsell, who knows how to bring out the best in students and children.

Thank you to Gavin Langley (Basement Jam) and dancers Elias and Michael, who allowed us access to their stepping video and to use the sequence in the film. 


\section{References}

Anderson A. 2014. Looking at documentaries. [Retrieved 29 April 2014] www.hotdocs.ca.

Ansari D \& Karmiloff-Smith A. 2002. A-typical trajectories of number development: a neuroconstructivist perspective. Trends in Cognitive Sciences, 6:511-516.

Bernard SC. 2014. Documentary Storytelling: The Drama of Real Life. [Retrieved 6 November 2014] http://www.writersstore.com/documentary-storytelling-thedrama-of-real-life/.

Butterworth B. 1999. The mathematical brain. London: Macmillan.

Butterworth B. 2012. Foundational numerical capacities and the origins of dyscalculia. In: S Dehaene \& EM Brannon (eds). Space, time and number in the brain. Searching for the foundations of mathematical thought. Amsterdam: Elsevier. 249-265.

Carey S. 2004. Bootstrapping and the Origin of Concepts. Daedalus, 33(1). [Retrieved 7 March 2010] http://www.jstor.org/stable/20027897.

CEPR (Centre for Education Practice Research). 2013. \#Taximaths - How children make their world mathematical. Johannesburg: University of Johannesburg.

Cross ES, Hamilton AF \& Grafton ST. 2006. Building a motor simulation de novo: Observation of dances by dancers. Neuroimage, 31(3):1257-1267.

Danesi M. 2007. The Quest for Meaning: A guide to semiotic theory and practice. Toronto: University of Toronto Press.

Daniels J. 2014. Teaching and Learning with Documentaries in the Digital Era. [Retrieved 30 April 2014] file:///C:/Users/Iragpot/Desktop/Documents/ UJ/Own\%20publications/2014/Film\%20as\%20TE\%20Genre/Articles/ Teaching $\% 20$ and $\% 2$ Learning $\% 20$ with $\% 20$ Documentaries $\% 20$ in $\% 20$ the $\% 20$ Digital\%20Era\%20\%20\%20JustPublics@365.htm.

Dehaene S. 2011. The number sense. How the mind creates mathematics. 2nd Edition. Cambridge: Oxford University Press.

Deely J. 2005. Basics of Semiotics. 4th Edition. Tartu: Tartu University Press.

Erasmus J. 2008. Celebrating heritage with dance. [Retrieved 6 November 2014] http:// www.mediaclubsouthafrica.com/culture/711-heritage030908.

Everydaytweet. In Simple Speak: What Does the \# Hashtag Symbol Mean on Twitter? [Retrieved 8 August 2014] http://www.everydaytweet.com/2009/04/what-doesthe-hashtag-symbol-mean-on-twitter.html.

Fritz A, Ehlert A \& Balzer L. 2013a. Development of mathemactical concepts as basis for an elaborated mathematical understanding. South African Journal of Childhood Education, 3(2):38-67.

Fritz A, Ricken G, Balzer L, Willmes K \& Leutner D. 2013b. Key numerical concepts at preschool and early primary school age: An integrative five-level model of cumulative arithmetic skills development. Early Childhood Research Quarterly.

Fuson KC. 1988. Children's counting and concepts of number. New York: Springer. 
Geary DC. 1993. Mathematical disabilities: cognition, neuropsychological and genetic components. Psychological Bulletin, 144:345-362.

Henning E. 2013. Teachers' understanding of mathematical cognition in childhood: Towards a shift in pedagogical content knowledge. Perspectives in Education, 31(3):139-154.

Henning E, Petker G \& Petersen N (in press). University-affiliated schools as sites for research learning in pre-service teacher education. South African Journal of Education, 35(1).

Henning E \& Ragpot L (in press). Pre-school children's bridge to symbolic knowledge: First framework for a cognition lab at a South African university. South African Journal of Psychology.

Kaufmann L \& Nuerk HC. 2005. Numerical development: current issues and future perspectives. Psychology Science, 47:142-170.

Miller TA. 2012. Encountering Attica: Documentary film-making as pedagogical tool. Journal of Legal Education, 62:231-239.

Nichols B. 2001. Introduction to Documentary. Bloomington, IN: Indiana University Press.

Parker D. 2010. The Foundation Phase Teacher Education Programme and Institutional Development Initiative of the DHET and the European Union. Address delivered at the launch of the SA Journal of Childhood Education. University of Johannesburg, 19 August. [Retrieved 15 September 2011] www.uj.ac.za/ujice.

Piaget J. 1965. The child's conception of number. New York: Norton.

Ragpot L. 2013. Student Learning in a Course on Cognitive Development in Childhood. Unpublished PhD thesis. Johannesburg: University of Johannesburg.

RSA DHET (Republic of South Africa. Department of Higher Education and Training). 2010. Draft Policy on the Minimum Requirements for Teacher Education Qualifications Aligned with the Higher Education Qualifications Framework. Pretoria: DHET.

Seligmann J \& Gravett S. 2010. Literacy development as 'a marginalised pedagogical service enterprise' or as social practice in the disciplines? Education as change. Journal of Curriculum Research, 14(1):107-120.

Smagorinsky P, Cook LS \& Johnson TS. 2003. The Twisting Path of Concept Development in Learning to Teach. Teachers College Records, 105(8):1399-1436.

Spelke ES. 2000. Core Knowledge. American Psychologist, 55(11):1233-1243.

Steffe LP, Cobb P \& Von Glasersfeld E. 1988. Construction of arithmetical meanings and strategies. New York: Springer Verlag.

Stevenson LM \& Deasy RJ. 2005. Third Space: When learning matters. Washington, DC: Arts Education Partnership.

Vygotsky L. 1978. Mind in society. The development of higher psychological processes. In: M Cole, VJ Steiner, S Scribner \& E Souberman (eds and transl). Cambridge, MA: Harvard University Press. 
Vygotsky LS. 1986. Thought and Language. Cambridge, MA: MIT Press.

Winner E \& Hetland L. 2007. Arts for our sake: School arts classes matter more than ever - but not for the reasons you think. Boston Globe. [Retrieved 1 April 2013] http://www.boston.com/news/globe/ideas/articles/2007/09/02/art_for_our_ sake/?page=full.

\section{Endnotes}

1. https://www.youtube.com/watch?v=5KLPxDtMqe8

2. http://eccl.mit.edu/

3. http://www.everydaytweet.com/2009/04/what-does-the-hashtag-symbol-mean-on-twitter. $\mathrm{html}$

4. Still photographs from the film may be viewed at http://www.uj.ac.za/EN/Faculties/edu/ CentresandInstitutes/CEPR/Pages/home.aspx, and the trailer may be viewed at http://youtu. be/x3VZVF4UsoQ.

5. https://www.youtube.com/watch?v=Uk4ZoXHp7Go

6. https://www.youtube.com/watch?v=TCNFEomRBWI 